\title{
Prevalence of Vertical Condilar Asymmetry of the Temporomandibular Joint in Patients with Signs and Symptoms of Temporomandibular Disorders
}

\author{
Prevalencia de Asimetría Condilar Vertical de la Articulación Temporomandibular \\ en Pacientes con Signos y Síntomas de Trastornos Temporomandibulares
}

*Verónica Iturriaga; **Pablo Navarro; *******Mario Cantin \& ***Ramón Fuentes

ITURRIAGA, V.; NAVARRO, P.; CANTÍN, M. \& FUENTES, R. Prevalence of vertical condilar asymmetry of the temporomandibular joint in patients with signs and symptoms of temporomandibular disorders. Int. J. Morphol., 30(1):315-321, 2012.

SUMMARY: Vertical condylar asymmetry (VCA) is considered a risk factor for the development of a temporomandibular disorder (TMD). VCA is determined by comparing the vertical condylar height between the left and right condyle. Several techniques have been developed to evaluate this asymmetry, and the most common among them are developed by Kjellberg et al. (1994) and Habets et al. (1988). The objective of this study was to evaluate the similarity of the Habets' and Kjellberg's methods with regard to these results and analyze the VCA results of the temporomandibular joint in patients with signs and symptoms of TMD. We analyzed 48 patients between 12 and 65 years of age. In each patient, the percentage of condylar symmetry according to the Kjellberg's and Habets' indexes was established and related to sex, age, and signs and symptoms of TMD at admission compared with patients who are symmetrical and asymmetrical. Finally, we compared the results of two indexes. According to Habets' index, $70.8 \%$ of patients were classified as asymmetric, compared with Kjellberg index where it was only $54.2 \%$. No statistically significant difference was found between the severity of signs and symptoms of TMD and sex, age, Habets' index, and Kjellberg's index. We also found no statistically significant difference between patient age and Kjellberg index, but between age and Habets' index, younger patients were symmetrical. We conclude that it is conceivable that the presence of VCA is not a risk factor for TMD development.

KEY WORDS: Condylar asymmetry; Temporomandibular joint; Temporomandibular disorder.

\section{INTRODUCTION}

The temporomandibular joint (TMJ) is a paired joint, where right and left joints are united by the mandible and work simultaneously for a proper function (Okeson, 2008). Commonly found in the body joints, a degree of disagreement on the left and right joint, so-called asymmetry, does not necessarily correspond to the presence of a disease but is considered a risk factor for the development of a temporomandibular disorder (TMD) (Fuentes et al., 2011).

In the TMJ, vertical condylar asymmetry (VCA) is determined by comparing the vertical condylar height between the left and right condyle (Saglam \& Sanli, 1994). Techniques have been developed to evaluate this asymmetry, some based on standardized measurements on panoramic radiograph, because of the relative technique simplicity and low-dose radiation that the patient is exposed (Kjellberg $e t$ al., 1994). The most common are those developed by
Kjellberg et al. and Habets et al. (1988). The first technique compares the ratios of condylar and ramus height on one side versus the other side obtaining a quotient of symmetry; in the second, linear calculation is performed by obtaining a quotient of asymmetry between the condylar height subtraction on the right and left side against the sum of these heights.

Condylar asymmetries have been associated with the presence of TMD. Buranastidporn et al. (2006) found a significant association between the presence of vertical asymmetry according to Habets index and the presence of internal TMD. Saglam \& Sanli determined an average of condylar asymmetry of $6.27 \pm 8.36 \%$ in healthy patients and $11.03 \pm 11.11 \%$ in patients with TMD using the Habets' method and found no statistically significant difference between the two groups ( $>00.05)$. Fuentes et al. (2006)

* Alumna del programa de Magíster en Odontología, Universidad de La Frontera, Temuco, Chile.

** Departamento Matemáticas y Estadística, Universidad de La Frontera, Temuco, Chile

*** Departamento Odontología Integral, Facultad de Odontología, Universidad de La Frontera, Temuco, Chile.

***** Doctorado en Ciencias Morfológicas, Universidad de la Frontera, Chile. 
obtained a prevalence of asymmetry by Habets' method in adolescents who consulted for orthodontic treatment of $26 \%$ in men and $41.1 \%$ in women; the same study also differentiates between different skeletal classes, concluding that the prevalence of asymmetry of the total sample is $20.2 \%$ in class I patients, $37.5 \%$ in class II patients, and $8.5 \%$ in class III patients $(\mathrm{n}=331)$.

Kjellberg et al. found a symmetry index of $93.7 \%$ in patients with class I molar and no signs or symptoms of TMD when comparing the height of the condylar process and mandibular height and $90.6 \%$ when comparing the height of the condylar process with the height of the mandibular ramus; an index of $93.7 \%$ and $90.1 \%$, respectively, in class II patients and a symmetry index of $89.5 \%$ and $86.8 \%$, respectively, in patients with joint disease.

Most studies of VCA diagnosed by panoramic radiograph refer to the validation of the latter as a test and validation of different techniques, but few studies compare the different techniques.

The aim of this study was to evaluate the TMJ vertical condylar asymmetry using two techniques described in patients with signs and symptoms of TMD treated at the polyclinic of TMDs at the Universidad de La Frontera Temuco, Chile.

\section{MATERIAL AND METHOD}

A cross-sectional study was designed where we reviewed the records of all patients who were treated at the polyclinic of TMDs between 2008 and June 2011. We excluded patients whose records did not contain panoramic radiograph or those that had been taken out of radiological university center and records without information on sex, age, registration of self-reported symptoms, and clinical signs of TMD (American Academy of Orofacial Pain, 1993). Also excluded were patients who did not present any signs or symptoms of TMD.

In each patient, the percentage of condylar symmetry according to the symmetry index (SI) of Kjellberg, and the percentage of condylar asymmetry according to the asymmetry index (AI) of Habets condyle were established, and they were related to sex, age, and signs and symptoms of TMD at admission compared with the symmetrical and asymmetrical patients. Finally, we compared the results of the two indexes.

Panoramic radiography. Conventional panoramic radiographs were used, which were made by a trained radiologist belonging to the radiology department of the Patient Care Teaching Unit Dental Clinic (CODA) of the Universidad de La Frontera, Temuco, Chile. The orthopantomograph

\section{A}

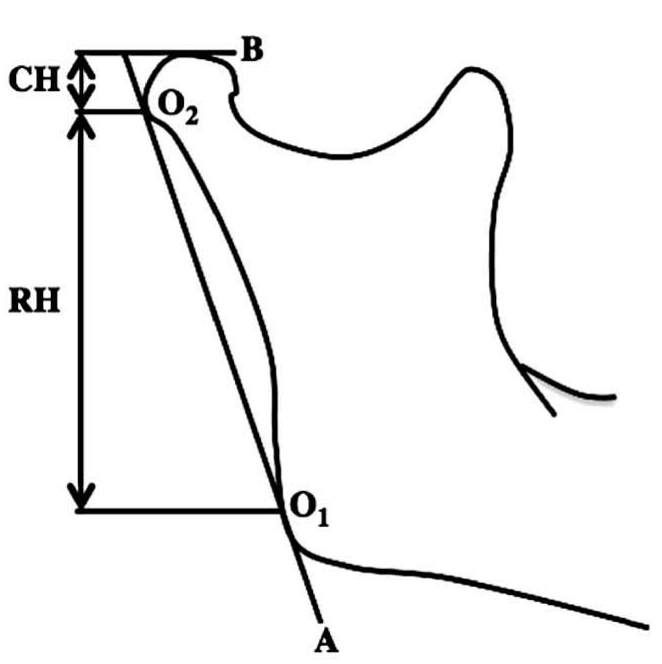

B

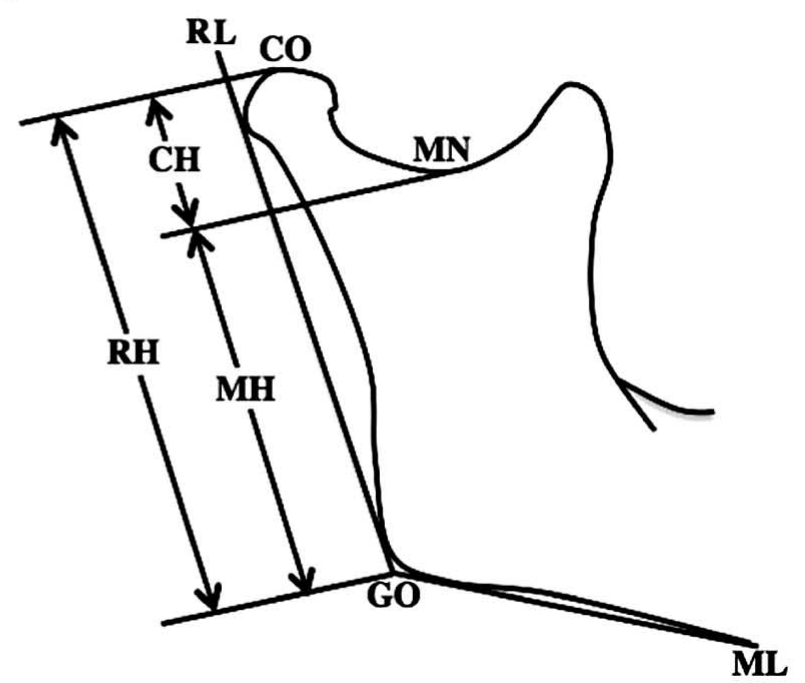

Fig. 1. A: Vertical condylar asymmetry index described by Habets. (B) the highest point of the condyle; (O2) the most lateral point of the condyle; (O1) the most lateral points of the mandibular ramus; $(\mathrm{RH})$ the mandibular ramus height and $(\mathrm{CH})$ condylar height. $\mathrm{B}$ : Diagram of measuring the condylar symmetry by Kjellberg's method. (CO) the highest point of the condylar head, (MN) mandibular notch, (GO) gonion, the intersection between the ramal line (RL) and the mandibular line (ML) that is tangential to the mandibular margin, (RL) tangential to the most posterior points of the condylar process and mandibular angle. These points are transferred to the RL to calculate these measurements in the vertical dimension, thereby defining the $\mathrm{CH}$ as the distance that goes from $\mathrm{CO}$ to $\mathrm{MN}$ measured above the RL, the mandibular height $(\mathrm{MH})$ as the distance between $\mathrm{MN}$ and $\mathrm{GO}$, and RH as the distance that goes from CO to GO. 
used was a BLUEX PantOs 16, with a magnification index of 1.30. Konica Minolta Films.

Condylar asymmetry. Condylar asymmetry measurements were performed by a single trained operator. Habets' and Kjellberg's methods were used for measurements according to the methodology previously reported by Fuentes (2011). The location points described in each technique are shown in Figure 1A and 1B. For Habets's method, a higher percentage to $6 \%$ is considered asymmetric. The index calculation was performed using the formula described in Figure 2.

\section{$\underset{\text { of Habets }}{\text { Asymmetry Index }(\mathrm{AI})}=\frac{(\text { Right } \mathrm{CH}-\text { Left } \mathrm{CH})}{(\text { Right } \mathrm{CH}+\text { Left } \mathrm{CH})} \times 100$}

Fig. 2. Formula for calculate condylar asymmetry according to Asymmetry Index (AI) of Habets.

SI can be calculated in two ways, using the two as separate indices. In the first value, SI1, the condylar height $(\mathrm{CH})$ and mandibular ramus height $(\mathrm{RH})$ values must be obtained. $\mathrm{CH}$ is defined as the distance from $\mathrm{CO}$ (the highest point of the condylar head) to MN (mandibular notch, the deepest point between the coronoid process and the condylar process), and $\mathrm{RH}$ as the distance from $\mathrm{CO}$ to GO (gonion); the calculation of the index is detailed in Figure 3. The second value, SI2, is obtained in the same way as the $\mathrm{CH}$ previously discussed, and the mandibular height $(\mathrm{MH})$ is defined as the distance between MN and GO. The calculation is as follows: the numerator should be smaller than the value resulting from the division of $\mathrm{CH}$ and $\mathrm{RH} / \mathrm{MH}$ regardless of whether it corresponds to the right or left joint.

Cutoff point for classifying patients was taken from the study by Kjellberg et al. where patients classified as normal in IS1 scored an average of $93.7 \%$, and those in IS2 scored
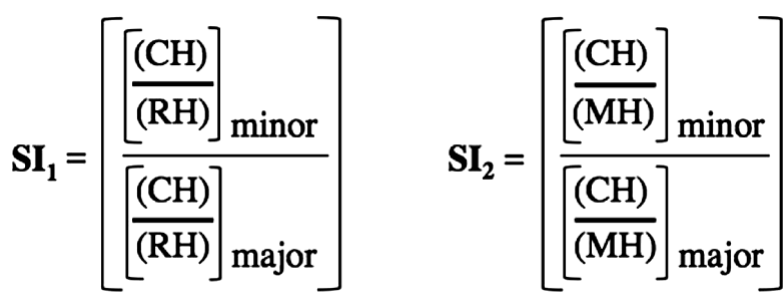

Fig. 3. Formula for calculate condylar symmetry according to Symmetry Index (SI) of Kjellberg, where there are formulas for SI1 and SI2.

an average of $90.3 \%$. Therefore, patients were classified as symmetrical to obtain a percentage of $93 \%$ or greater and asymmetric to get a lesser value in the first case (IS1), and in the second case (IS2), the patients with percentage higher or equal to $90 \%$ were classified as symmetric, and those with percentage lower than $90 \%$ were classified as asymmetric.

Symptoms at admission. The symptomatology was obtained at entry through self-report questionnaire of signs and symptoms of TMD (SS) recommended by the American Academy of Orofacial Pain. SS questionnaire contained 10 questions, which refer to various signs and symptoms that suggest a TMD (Table I).

Patients were arbitrarily classified according to the number of questions answered positively, 1-3 was considered mild, 4-6 moderate, and 7-10 severe.

Statistical analysis. Statistical analysis was performed using descriptive statistics in the corresponding case. The distribution between variables were measured using analysis of variance test $(95 \%$, considered statistically significant, $p<0.05)$, and Bartlett's test was used to measure the homogeneity of variances.

Table I. Self-report questionnaire of symptoms (SS) of TMD applied to the patient upon admission (Recommended for TMD by the American Academy of Orofacial Pain).

\begin{tabular}{|c|c|c|c|}
\hline \multicolumn{2}{|r|}{ Questions } & \multicolumn{2}{|c|}{ Respond } \\
\hline & & Yes & No \\
\hline 1 & Do you have difficulty, pain or both when opening your mouth or when yawning? & & \\
\hline 2 & Does your jaw get stuck, or lock, or go out? & & \\
\hline 3 & Do you have difficulty, pain, or both when chewing, talking, or using your jaw? & & \\
\hline 4 & Are you aware of noises in the jaw joint? & & \\
\hline 5 & Do your jaws regularly feel stiff, tired, or tight? & & \\
\hline 6 & Do you have pain in or about the ears, temples, or cheeks? & & \\
\hline 7 & Do you have frequent headaches, neckaches or unexplained toothaches? & & \\
\hline 8 & Have you had a recent injury to your head, neck, or jaw? & & \\
\hline 9 & Have you been aware of any recent changes in your bite? & & \\
\hline 10 & Have you been previously treated for unexplained facial pain or a jaw joint problem? & & \\
\hline
\end{tabular}




\section{RESULTS}

The sample consisted of 48 patients, with a mean age of 29.4 (SD 15.7) years, ranging from 12 to 65 years; $85.4 \%$ of the patients were women $(n=41)$, and $14.6 \%$ were men $(n=7)$. It was found that $8.3 \%(n=4)$ had mild symptoms, $35.4 \%(n=17)$ had moderate, and $56.3 \%$ $(\mathrm{n}=27)$ had severe TMD symptoms. Of the total sample according to Habets' AI, 70.8\% ( $n=34)$ were classified as asymmetric, compared with that according to Kjellberg where $54.2 \%(n=26)$ of the patients were asymmetric in both IS1 and IS2 (Table II).

Table II. Details of the results of Habets's asymmetry index (AI) and Kjellberg's indexes (SI1 and SI2). It shows the presence and absence of asymmetry for different indexes and percentages are broken down further according to the SS of TMD classified as mild, moderate and severe.

\begin{tabular}{lcccccc}
\hline & AI & \% & SI $_{\mathbf{1}}$ & \% & SI $_{2}$ & \% \\
\cline { 2 - 7 } Total asymmetry & 34 & 70.8 & 26 & 54.2 & 26 & 54.2 \\
Total symmetry & 14 & 29.2 & 22 & 45.8 & 22 & 45.8 \\
Asymmetric - SS mild & 2 & 4 & 1 & 2 & 1 & 2 \\
Symmetric - SS mild & 2 & 4 & 3 & 6 & 3 & 6 \\
Asymmetric - SS moderate & 12 & 25 & 9 & 19 & 9 & 19 \\
Symmetric - SS moderate & 5 & 10 & 8 & 17 & 8 & 17 \\
Asymmetric - SS severe & 20 & 42 & 16 & 33 & 16 & 33 \\
Symmetric - SS severe & 7 & 15 & 11 & 23 & 11 & 23 \\
\hline
\end{tabular}

Among the three techniques, there was agreement in $52.1 \%$ regardless of the outcome of symmetry or asymmetry, where $39.6 \%$ of the patients are asymmetric matches and $12.5 \%$ are symmetrical. Furthermore, the population was distributed evenly into the three techniques. The average index values in patients broken down according to the symmetric and asymmetric Habets' index resulted in an average of $16.7 \%$ asymmetrical patients and $3.5 \%$ symmetrical patients. In the method of Kjellberg in S1, the average asymmetry values were $87.5 \%$, and the symmetry values were $96.6 \%$. Finally, in the S2, the average asymmetry and symmetry values were $83.1 \% 95.2 \%$, respectively (Table III).

By comparing the positive values in the questionnaire of signs and symptoms of TMD with sex, we found that with a significance level of $5 \%$, the population means of the values in women are approximately equal those in men $(\mathrm{p}=0.8772)$. On the other hand, according to Bartlett's test, we can conclude that the population variances were homogeneous ( $\mathrm{p}=0.329)$ (Fig. 4).

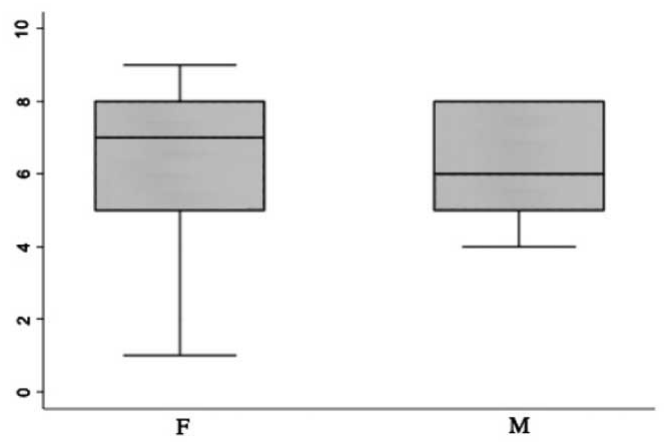

Fig. 4. Distribution of the value assigned in the Self-report questionnaire signs and symptoms of TMD (0-10). $\mathrm{F}=$ female, $\mathrm{M}=$ male.

The age was assessed with respect to the result of asymmetry and symmetry in the three indices (statistical significance, 5\%); in Habets' index, the mean age of the symmetrical population were different to that of the asymmetrical population $(\mathrm{p}=0.0300)$, where the symmetrical patients belong to an age group of patients younger than the asymmetric ones but with a homogeneous variance $(\mathrm{p}=0.733)$ (Fig. 5A). IS 1 Kjellberg index showed a mean population very similar between the asymmetric and symmetric groups $(\mathrm{p}=0.7156)$, with a homogeneity of variances $(\mathrm{p}=0.262)$ (Fig. 5B). IS2 Kjellberg index showed the same results ( $p=0.6909$ and $p=0.929$, respectively) (Fig. 5C).

In terms of age and severity of signs and symptoms of TMD, no statistically significant difference was found between the mean age of the population with signs and symptoms that are mild, moderate, and severe $(\mathrm{p}=0.467)$ and with homogeneous variances $(\mathrm{p}=0.690)$ (Fig. 6).

Table III. Average values of asymmetry and symmetry as each method, Habets's index (AI), Kjellberg's index S1 (SI1) and Kjellberg's index S2 (SI2).

\begin{tabular}{lcccccc}
\hline Indexes & Total Average & SD & Min. & Max. & Average asymmetry $(\%)$ & Average symmetry (\%) \\
\hline AI & 12.8 & 10.7 & 0 & 47.8 & 16.7 & 3.5 \\
SI $_{\mathbf{1}}$ & 91.7 & 5.6 & 78.3 & 99.6 & 87.5 & 96.6 \\
SI $_{2}$ & 88.6 & 7.4 & 70.5 & 99.2 & 83.1 & 95.2 \\
\hline
\end{tabular}


$\mathbf{A}$

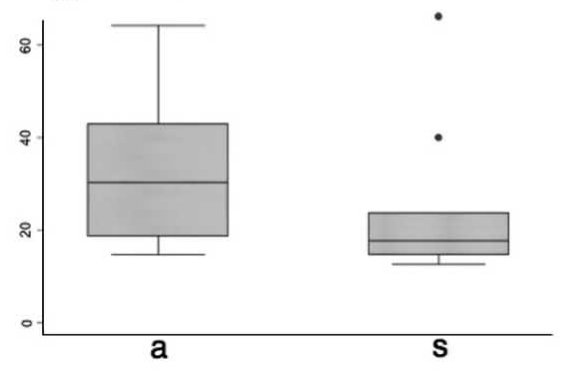

B

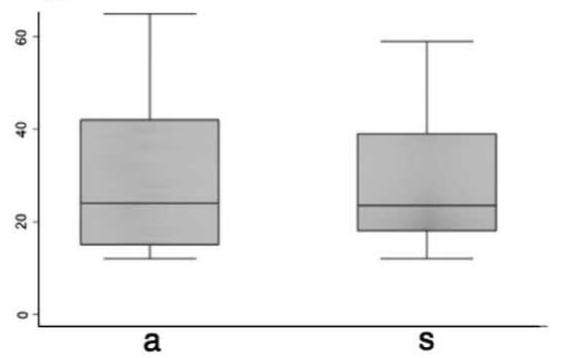

C

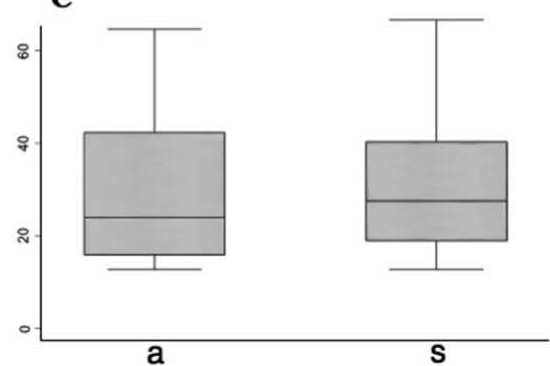

Fig. 5. Age distribution of patients with respect to A: Habets index, B: Kjellberg index 1 and C: Kjellberg index 2. $a=$ asymmetric, $\mathrm{s}=$ symmetric.

Finally, in comparing the population mean severity (mild, moderate, and severe) according to each index, there are similarities between the three non-statistically significant difference between the severity of signs and symptoms of TMD and the individual results of each index (Fig. 7).

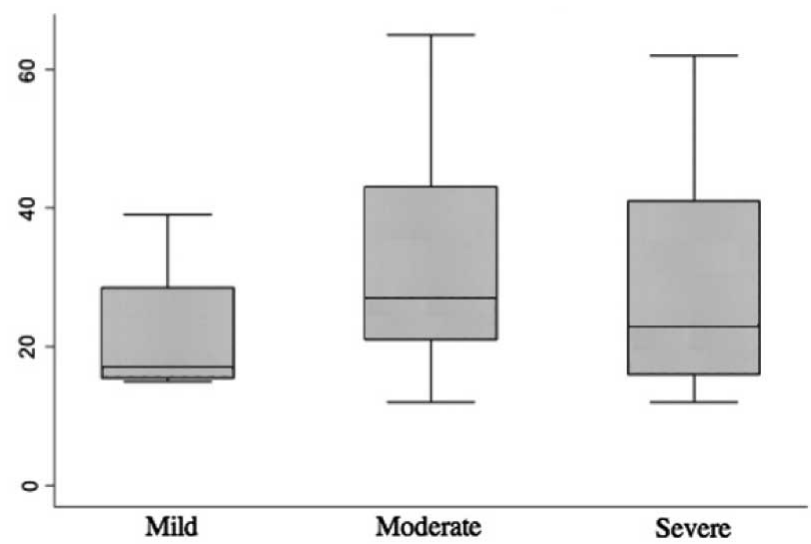

Fig. 6. Distribution of patients regarding their age and the severity of the signs and symptoms reported in the Self-report questionnaire at admission.

\section{DISCUSSION}

TMD disorders are considered the most prevalent source of chronic orofacial pain (Dworkin et al., 1990; Yap et al., 2003), with a set of conditions that affect this area. Studies show that $6 \%$ to $93 \%$ of the general population has or had any signs and symptoms of TMD (Locker \& Slade, 1988; De Kanter et al., 1993). The presence of signs and symptoms of TMD has been found in all age groups, focusing mostly on 20 and 40 (Tallents et al., 1991; Levitt \& McKinney, 1994). The present study shows a wide age range from 15 to 65 years but without a specific mode.

It is proposed that in older adults, TMD symptoms would be minor compared with that in the general population; however, in this group, the signs of TMD would increase (Dworkin et al.; Levitt \& McKinney), including the signs and symptoms of TMD in child and adolescent patients, but these would be minor (Thilander et al., 2002). According to the data collected in this study, the severity of signs and symptoms did not vary significantly with age.
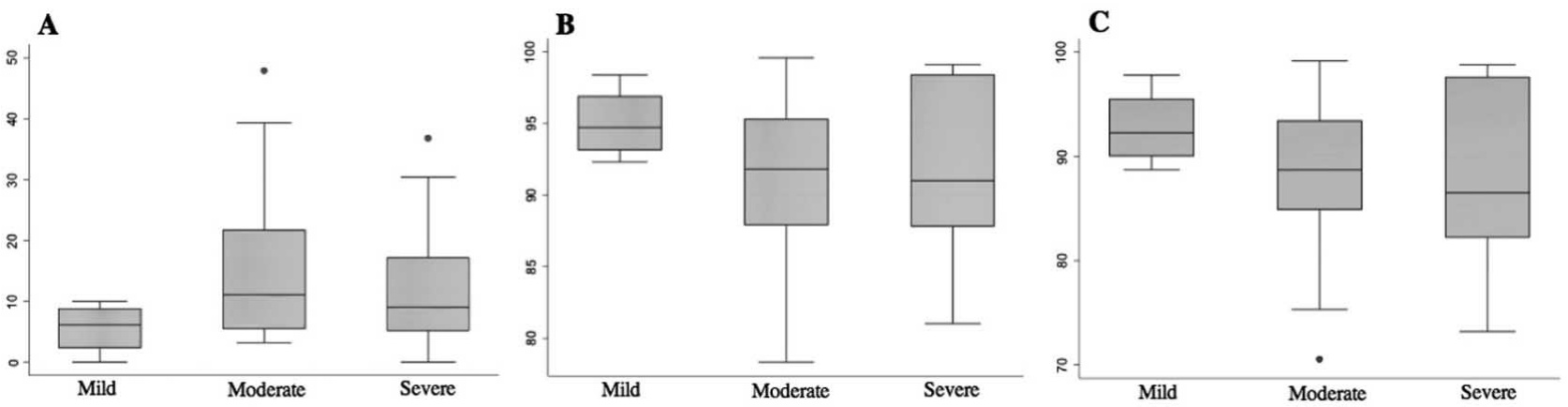

Fig. 7. Distribution of patients regarding the severity of signs and symptoms of TMD (mild, moderate and severe) regarding the outcome of the index of A: Habets, B: Kjellberg 1 and C: Kjellberg 2. 
Consistent with some studies (LeResche, 1997; White et al., 2001; Anastassaki \& Magnusson, 2004), in our results female patients were those with more consultation on treatment compared with male patients, suggesting a greater severity of disease. However, unlike some studies that mentioned that there would be an increase in symptoms by the women in our study sample was homogeneous in terms of severity of signs and symptoms (LeResche; Magnusson et al., 2000).

With respect to the presence of VCA, some previous studies found no difference between the age of the patients and the asymmetry index measured by the Habets' index (Miller \& Bodner, 1997; Miller \& Smidt, 1996), which differs from the results found in this study for Habets' index but not from the results obtained with the two Kjellberg's indexes where there is no significant difference in the ages of the patients.

Saglam \& Sanli report that the average of Habets' asymmetry index in patients with TMD of muscular origin was $11.11 \%$ compared with that in the study by Habets $e t$ $a l$. in patients with articular TMD where the average was $7.3 \%$. The average Habets' asymmetry index in patients of this study was $12.8 \%$ being in proximity to the previous results.

Kjellberg et al. reported that patients with pathology of articular origin, specifically juvenile arthritis, had an average Kjellberg's IS1 of $89.5 \%$ and Kjellberg's IS2 of $86.8 \%$, which, when compared with the obtained results, showed that the average index in patients with signs and symptoms of TMD of $91.7 \%$ and $88.6 \%$, respectively, is quite similar.

With regard to the different indices and the number of symmetric and asymmetric patients, coincidences are rather low: the Habets' index has a greater number of asymmetric patients $(70.8 \%)$ compared with the two
Kjellberg's indices that indicate that $54.2 \%$ of patients are asymmetric. This shows that the methods are not comparable. This was predictable because they take different technical benchmarks for measurement, and calculation of the index is done differently. We believe that the Habets' method is more complicated when making reference points, as there often is a very slight difference between the upper point of the condyle and the most lateral point of it; also, the mathematical relationship used is only linear compared with condylar heights, not taking into account a condylar height ratio and mandibular height or mandibular ramus height, which could increase the number of false positives.

Fuentes et al. (2011) compared the Kjellberg's and Habets' methods in the degree of distortion in the $\mathrm{x}$-ray that would allow small horizontal movements of the head, concluding that both techniques gave acceptable clinical information but stated that the Kjellberg's method is easier to perform in terms of identifying and measuring points.

Importantly according to the results, the prevalence of condylar asymmetry is high and cannot be dismissed as a possible risk factor for developing a TMD, but studies are needed in healthy patients because the asymmetry or symmetry of the patients did not indicate an increase in the severity of signs and symptoms of TMD, which could rule out the presence of an asymmetry as a determinant in the severity of the disease.

Finally, a guideline for future research is necessary to delve into topics such as general population prevalence of VCA, presence of asymmetry in patients without a TMD, or condylar asymmetry as a risk factor for developing TMD performed in prospective studies. Therefore, it is suggested that further investigations be conducted to bring the resolution to this problem.

ITURRIAGA, V.; NAVARRO, P.; CANTíN, M. \& FUENTES, R. Prevalencia de asimetría condilar vertical de la articulación temporomandibular en pacientes con signos y síntomas de trastornos temporomandibulares. Int. J. Morphol., 30(1):315-321, 2012.

RESUMEN: La asimetría condilar vertical (ACV) es considerada un factor de riesgo para el desarrollo de un Trastorno Temporomandibular (TTM). ACV se determina al comparar la altura condilar vertical entre el cóndilo derecho e izquierdo. Se han desarrollado diversas técnicas para evaluar esta asimetría, las más conocidas son las desarrolladas por Kjellberg et al. (1994) y Habets et al. (1988). El Objetivo de éste estudio fue evaluar la similitud de la técnica de Habets con la técnica de Kjellberg en cuanto a los resultados y analizar éstos resultados de ACV de la articulación temporomandibular en pacientes con signos y síntomas de un trastorno temporomandibular. Se analizaron 48 pacientes entre 12 y 65 años. En cada paciente se estableció el porcentaje de simetría condilar según el índice de Kjellberg y el índice de Habets y se relacionó con las variables sexo, edad, y signos y síntomas de TTM al momento del ingreso con respecto a los pacientes simétricos y asimétricos. Por último se compararon los resultados de ambos índices. Según el índice de Habets el 70,8\% de los pacientes fue clasificado como asimétrico, en comparación con kjellberg donde fue solo el 54,2\%. No se encontró diferencia estadísticamente significativa entre la severidad de los signos y síntomas de un trastorno temporomandibular y las variables sexo, edad, índice de Habets e índice de Kjellberg. Tampoco se encontró diferencia estadísticamente significativa entre la edad de los pacientes y el índice de Kjellberg, pero si se encontró diferencia entre la edad y el índice de Habets donde los pacientes simétricos tenían menor edad. Se concluye que es posible pensar que la presencia de ACV no representa un factor de riesgo para el desarrollo de un TTM.

PALABRAS CLAVE: Asimetría condilar; Articulación temporomandibular; Trastornos temporomandibulares. 


\section{REFERENCES}

American Academy of Orofacial Pain. Temporomandibular disorders: guidelines for classification, assessment, and management. Chicago, Quintessence, 1993.

Anastassaki, A. \& Magnusson, T. Patients referred to a specialist clinic because of suspected temporomandibular disorders: a survey of 3194 patients in respect of diagnoses, treatments, and treatment outcome. Acta Odontol. Scand., 62(4):183-92, 2004.

Buranastidporn, B.; Hisano, M. \& Soma, K. Temporomandibular joint internal derangement in mandibular asymmetry. What is the relationship? Eur. J. Orthod., 28(1):83-8, 2006.

De Kanter, R. J.; Truin, G. J.; Burgersdijk, R. C.; Van't Hof, M. A.; Battistuzzi, P. G.; Kalsbeek, H. \& Käyser, A. F. Prevalence in the Dutch adult population and a meta-analysis of signs and symptoms of temporomandibular disorder. J. Dent. Res., 72(11):1509-18, 1993.

Dworkin, S. F.; Huggins, K. H.; LeResche, L.; Von Korff, M.; Howard, J.; Truelove, E. \& Sommers, E. Epidemiology of signs and symptoms in temporomandibular disorders: clinical signs in cases and controls. J. Am. Dent. Assoc., 120(3):273-81, 1990.

Fuentes, R.; Engelke, W.; Bustos, L.; Oporto, G.; Borie, E.; Sandoval, P.; Garay, I.; Bizama, M. \& Borques, P. Reliability of tow radiographic methods to assess condilar asymmetry. Int. J. Morphol., 29(3):694-701, 2011.

Fuentes, R.; Silva, H., Sandoval, P.; Cuevas, F. \& Rodríguez, M. Height of the condilar process in different esqueletal class who require orthodontic treatment. Int. J. Morphol., 24(3):499-503, 2006.

Habets, L. L.; Bezuur, J. N.; Naeiji, M. \& Hansson, T. L. The Orthopantomogram, an aid in diagnosis of temporomandibular joint problems. II. The vertical symmetry. J. Oral Rehabil., 15(5):465-71, 1988.

Kjellberg, H.; Ekestubbe, A.; Kiliaridis, S. \& Thilander, B. Condylar height on panoramic radiographs. A methodologic study with a clinical application. Acta Odontol. Scand., 52(1):43-50, 1994.

LeResche, L. Epidemiology of temporomandibular disorders: implications for the investigation of etiologic factors. Crit. Rev. Oral Biol. Med., 8(3):291-305, 1997.

Levitt, S. R. \& McKinney, M. W. Validating the TMJ scale in a national sample of 10,000 patients: demographic and epidemiologic characteristics. J. Orofac. Pain, 8(1):25-35, 1994.

Locker, D. \& Slade, G. Prevalence of symptoms associated with temporomandibular disorders in a Canadian population. Community Dent. Oral Epidemiol., 16(5):310-3, 1988.
Magnusson, T.; Egermark, I. \& Carlsson, G. E. A longitudinal epidemiologic study of signs and symptoms of temporomandibular disorders from 15 to 35 years of age. $J$. Orofac. Pain, 14(4):310-9, 2000.

Miller, V. J. \& Bodner, L. Condylar asymmetry measurements in patients with an Angle's Class III malocclusion. J. Oral Rehabil., 24(3):247-9, 1997.

Miller, V. J. \& Smidt, A. Condylar asymmetry and age in patients with an Angle's Class II division 2 malocclusion. J. Oral Rehabil., 23(10):712-5, 1996.

Okeson, J. P. Tratamiento de oclusión y afecciones temporomandibulares. $6^{\mathrm{a}}$ Ed. Madrid, Elsevier, 2008.

Saglam, A. A. \& Sanli, G. Condylar asymmetry measurements in patients with temporomandibular disorders. J. Contemp. Dent. Pract., 5(3):59-65, 2004.

Tallents, R. H.; Catania, J. \& Sommers, E. Temporomandibular joint findings in pediatric populations and young adults: a critical review. Angle Orthod., 61(1):7-16, 1991.

Thilander, B.; Rubio, G.; Pena, L. \& de Mayorga, C. Prevalence of temporomandibular dysfunction and its association with malocclusion in children and adolescents: an epidemiologic study related to specified stages of dental development. Angle Orthod., 72(2):146-54, 2002.

White, B. A.; Williams, L. A. \& Leben, J. R. Health care utilization and cost among health maintenance organization members with temporomandibular disorders. J. Orofac. Pain, 15(2):158-69, 2001 .

Yap, A. U.; Dworkin, S. F.; Chua, E. K.; List, T.; Tan, K. B. \& Tan, H. H. Prevalence of temporomandibular disorder subtypes, psychologic distress, and psychosocial dysfunction in Asian patients. J. Orofac. Pain, 17(1):21-8, 2003.

\section{Correspondence to: \\ Ramón Fuentes \\ Dentistry Department \\ Faculty of Medicine \\ Universidad de La Frontera \\ Av. Francisco Salazar 01145, Temuco \\ CHILE}

Email: rfuentes@ufro.cl

Received: 22-11-2011

Accepted: 22-12-2011 